\title{
Endoscopists' opinions of indications for upper gastrointestinal endoscopy
}

\author{
LLOYD R SUTHERLAND MDCM MSc FRCPC FACP, MARJA J VERHOEF PhD, JONATHAN B MEDDINGS MD FRCPC, \\ ROBERT J BAILEY MD FRCPC, PHILIP B BLUSTEIN MD FRCPC, EOIN A LALOR MB ChB FRCPC FRACP, \\ ALAN BR THOMSON MD PhD FRCPC FACG, GUIDO M VAN ROSENDAAL MD FRCPC
}

\begin{abstract}
LR Sutherland, MJ Verhoef, JB Meddings, et AL. Endoscopists' opinions of indications for upper gastrointestinal endoscopy. Can J Gastroenterol 1997;11(3):221-227.
\end{abstract}

OBJECTIVE: To determine whether endoscopists and general internists agreed with the characterization of appropriateness for endoscopy of various clinical scenarios, as previously reported by the RAND Corporation

DESIGN: Mail survey.

STUDY SAMPLE: All endoscopists in western Canada and a random sample of general internists who did not perform endoscopy.

METHODS: Questionnaires were sent to 179 endoscopists in western Canada who were asked to rate the 53 scenarios for endoscopy on a nine-point scale ranging from most appropriate to most inappropriate. A similar questionnaire was sent to 39 general internists practising in the province of Alberta.

RESULTS: Response rate was $72 \%$ of endoscopists $(n=128)$ and $64 \%$ of general internists $(n=25)$. Among the endoscopists, there was agreement with the RAND classification for 32 scenarios. All 18 indications previously thought to be appropriate were considered to be appropriate. However, endoscopists agreed with only six of 16 equivocal and eight of 19 indications considered inappropriate. Discrepancies were reviewed by five experienced endoscopists and most appeared to be related to a concern regarding possible malignancy linked in part with the definition of failure to respond to medical therapy; and to a refusal to request a barium meal before endoscopy. Among general internists, there was agreement with RAND in 26 scenarios. When the appropriateness rankings of endoscopists and general internists were compared, there was agreement in 40 of 53 scenarios. Significant discrepancies in ratings were identified in scenarios in which barium studies were described as being normal, known or not done.
CONCLUSIONS: The equivocal and inappropriate ratings developed by the RAND Corporation are not uniformly accepted by the endoscopy community or general internists. Use of the RAND indications for assessing quality assurance can be challenged.

Key Words: Endoscopy, Indications, Survey

\section{Opinions des endoscopistes sur les indications de l'endoscopie des voies digestives hautes}

OBJECTIF : Vérifier si les endoscopistes et les internistes généraux s'entendent sur le bien-fondé de l'endoscopie appliquée à divers scénarios cliniques, comme en faisait état un rapport antérieur de la corporation RAND.

MODÈLE : Sondage par la poste.

ÉCHANTILLON ÉTUDIÉ : Tous les endoscopistes et un échantillon aléatoire d'internistes généraux de l'Ouest du Canada qui effectuent des endoscopies.

MÉTHODES : Les questionnaires ont été envoyés à 179 endoscopistes de l'Ouest du Canada à qui on a demandé de classer 53 scénarios d'endoscopie sur une échelle en neuf points, allant du plus au moins approprié. Un questionnaire semblable a été expédié à 39 internistes généraux de la province de l'Alberta.

RÉSULTATS : Le taux de réponse a été de $72 \%$ pour les endoscopistes $(\mathrm{n}=128)$ et de $64 \%$ pour les internistes généraux $(\mathrm{n}=25)$. Parmi les endoscopistes, on a noté une concordance avec la classification de RAND pour 32 scénarios. Les 18 indications auparavant jugées appropriées ont été jugées appropriées. Toutefois, les endoscopistes ne se sont entendus que sur 6 des 16 indications jugées équivoques et sur 8 des 19 indications jugées inappropriées. Les discordances ont été passées en revue par cinq endoscopistes d'expérience et la plupart ont semblé avoir trait au doute suscité par la présence possible d'une néoplasie associée en partie à l'échec d'un traitement médicamenteux et à un refus de demander un repas baryté avant

voir page suivante

Departments of Medicine and Community Health Sciences, University of Calgary, Calgary; and the Department of Medicine, University of Alberta, Edmonton, Alberta

Correspondence and reprints: Dr Lloyd R Sutherland, 3330 Hospital Drive NW, Calgary, Alberta T2N 4N1. Telephone 403-220-7181, fax 403-270-7307, e-mail lsutherl@acs.ucalgary.ca

Received for publication April 16, 1996. Accepted September 6, 1996 
l'endoscopie. Chez les internistes généraux, on a noté une concordance avec la classification de RAND pour 26 scénarios. Lorsque la classification du bien-fondé des endoscopistes et des internistes généraux ont été comparées, on a noté une concordance de 40 scénarios sur 53. Les discordances significatives quant au classement ont été identifiées pour les scénarios dans le cadre desquels les épreuves au baryum étaient décrites comme étant nor- males, connues ou non effectuées.

CONCLUSIONS : Les classifications équivoques et inappropriées établies par la corporation RAND ne sont pas uniformément acceptées par la communauté des endoscopistes ou des internistes généraux. Le recours aux indications de la corporation RAND pour l'évaluation de l'assurance de la qualité peut devoir être remis en question.
U pper gastrointestinal endoscopy has revolutionized the diagnosis and treatment of gastrointestinal disease. It may be used to evaluate a variety of signs, symptoms and laboratory abnormalities in patients who range from well to critically ill. Endoscopy has been found to be more accurate, sensitive and specific than radiological techniques and barium studies. The result has been a tremendous increase in the number of endoscopies performed $(1,2)$. As previous studies have noted, the majority of patients have either normal examinations or minor/insignificant disease (3). It is unclear whether increased use of endoscopy has provided benefit to patients or society. Also, it has been suggested that the increased use of endoscopy does not influence the diagnosis or prognosis of gastric cancer (4) or the rate of major complications of peptic ulcer disease (5). The rate of increase in endoscopic procedures can be altered through the introduction of quality assurance programs (2). A first step in any quality assurance program should be to develop appropriate indications for endoscopy.

One of the very few studies related to the appropriate indications for endoscopy was conducted by RAND Corporation (6). The process was as follows. In 1981 a detailed list of 1069 indications for specific clinical scenarios for which gastrointestinal endoscopy might be used was developed from detailed literature reviews and the input of experts. The scenarios categorized patients according to symptoms, previous history, use of medications and results of previous diagnostic tests. In 1983, using a modified Delphi technique (ie, limiting the discussion to a group of experts in the field), a national panel of nine physicians with diverse backgrounds and expertise rated each indication on a nine-point scale of appropriateness (ranging from $1=$ extremely appropriate to 9 = extremely inappropriate). The panel defined appropriateness as the condition in which the expected health benefit (ie, increased life expectancy, relief of pain, reduction in anxiety and improved functional capacity) exceeded the expected negative consequences of doing the procedure (ie, mortality, morbidity, anxiety of anticipating the procedure, misleading or false diagnosis, pain produced from the procedure and time lost from work) by a sufficiently wide margin that the procedure was worth doing. Before assigning the appropriateness ratings, the panel revised the initial set of indications and discussed the exact definitions of the indications with the researchers. An indication was considered appropriate if the median panel rating was 1, 2 or 3 without disagreement. An indication was considered inappropriate if the median panel rating was 7,8 or 9 without disagreement. An indication was considered equivocal if the median rating was 4, 5 or 6 regardless of disagreement or whether panelists disagreed on the appropriateness of indications with median rating of 1 to 3 or 7 to 9 .

In 1981 the RAND group also performed a detailed medical record review of a random sample of 1585 patients aged 65 and older who had upper gastrointestinal endoscopy in order to assess the appropriateness of using endoscopy. Based on these data, the RAND group found that, overall, $72 \%$ of the endoscopies were done for appropriate indications, $11 \%$ for equivocal indications and $17 \%$ for inappropriate indications. Upper gastrointestinal bleeding (26\%), follow-up to an abnormal upper gastrointestinal series (21\%), dysphagia $(18 \%)$ and dyspepsia $(15 \%)$ were the most frequent clinical reasons for ordering endoscopy. A typical appropriate scenario was investigation of dysphagia in a patient with an anatomical esophageal defect evident on barium study. In contrast, endoscopy in a patient with dyspepsia, a normal barium study and an inadequate course of medical therapy was considered inappropriate.

Several limitations of the RAND study have been noted since publication of the results. A major limitation was that the RAND findings were applicable to endoscopies performed in 1981 and indications developed in 1981, which might be not be applicable today. In 1981, endoscopy was still in its infancy (7). Also, during the past few years barium studies have been replaced by endoscopy (8), and there can be fear of malignancy in scenarios referring to an inadequate trial of medical therapy, which currently would be considered as an appropriate reason for endoscopy (9). In addition, there was lack of clarity regarding the RAND definition of inadequate therapy (9).

Evaluation of the RAND indications in the Canadian context is still important given the differences between the Canadian and American health care systems. For example, in the RAND study panelists were instructed to ignore the cost of the procedure in their evaluations, yet it has been stated that "cost is probably the major deterrent to more widespread use of endoscopy in [the United States]" (10).

Despite criticisms of the RAND study, there has not been a structured survey of endoscopists' opinions regarding the scenarios. With the increasing demand for quality assurance programs, reviewers may wish to refer to previous work done by experts. The RAND criteria could form the basis for such a review of the appropriate indications for endoscopy.

Using the 53 most frequently occurring appropriate, equivocal and inappropriate indications as selected by RAND (see the Appendix), the objectives of our study were to determine, first, whether endoscopists in western Canada, 10 years later, agreed with the RAND ratings; second, reasons for any disagreement; third, whether physician and 
practice characteristics are related to indication ratings; and, finally, whether ratings from general internists differ from those of endoscopists.

\section{MATERIAL AND METHODS}

This was a cross-sectional study of physicians performing endoscopy. Questionnaires were mailed to the administrators of all acute care facilities in the province of Alberta. Each hospital was asked to distribute the questionnaire to any endoscopists in their facility. Questionnaires were also sent directly to all endoscopists practising at the four hospitals participating in the Alberta Endoscopy Project (Calgary General Hospital, Calgary; and Foothills Hospital, Royal Alexandra Hospital and the University of Alberta Hospital, Edmonton). Finally, questionnaires were mailed to all members of the Canadian Association of Gastroenterology who reside in British Columbia, Alberta, Saskatchewan and Manitoba. To be eligible, physicians had to perform at least 25 endoscopies per year. Pediatric gastroenterologists were excluded.

To evaluate the endoscopists' ratings and compare them with those of a group who may have less direct interest in endoscopy, a similar questionnaire was sent to communitybased general internists in Calgary and Edmonton. Only general internists who did not perform endoscopies but did refer patients for endoscopy were eligible. In the Canadian context, general internists see the majority of their patients by referral from family practitioners and would not consider themselves to be providers of primary care.

The questionnaire components included demographic characteristics, practice pattern, available endoscopy facilities and the 53 published RAND scenarios, which were similar to those in the RAND study and were to be graded on a nine-point scale. The 53 scenarios were placed in random order and the endoscopists were not made aware of the RAND rating. (The questionnaire is available upon request from the corresponding author.)

Distribution for ratings for the different (sub)groups were compared using the Mann-Whitney $U$ test for two independent samples or the Krushal-Wallis one-way ANOVA for $\mathrm{K}$ independent samples. The statistical software package SPSS (SPSS Inc, Illinois) was used to analyze the data. An alpha criterion of 0.05 or less was used to indicate statistical significance.

\section{RESULTS}

Description of the sample: Of the 179 eligible endoscopists who were identified, $128(72 \%)$ completed and returned the questionnaire. Mean age of the endoscopists was 46.3 years; the majority were gastroenterologists $(54 \%)$, followed by surgeons (27\%), general internists (10\%) and others (9\%). The majority $(75 \%)$ of the respondents spent at least $75 \%$ of their time in clinical care. Sixty-eight per cent had recently attended a continuing medical education or other educational event. Fourteen per cent practised in a hospital with fewer than 100 beds, 24\% in a hospital with 101 to 300 beds, $51 \%$ in a hospital with 301 to 800 beds and $11 \%$ in a hospital

\section{TABLE 1}

Median RAND Corporation ratings compared with those from this study

\begin{tabular}{lr}
\hline Considered appropriate by RAND & 18 \\
Considered appropriate by study sample & 18 \\
Considered equivocal by RAND & 16 \\
Considered appropriate by study sample & 10 \\
Considered equivocal by study sample & 6 \\
Considered inappropriate by RAND & 19 \\
Considered appropriate by study sample & 5 \\
Considered equivocal by study sample & 6 \\
Considered inappropriate by study sample & 8 \\
\hline
\end{tabular}

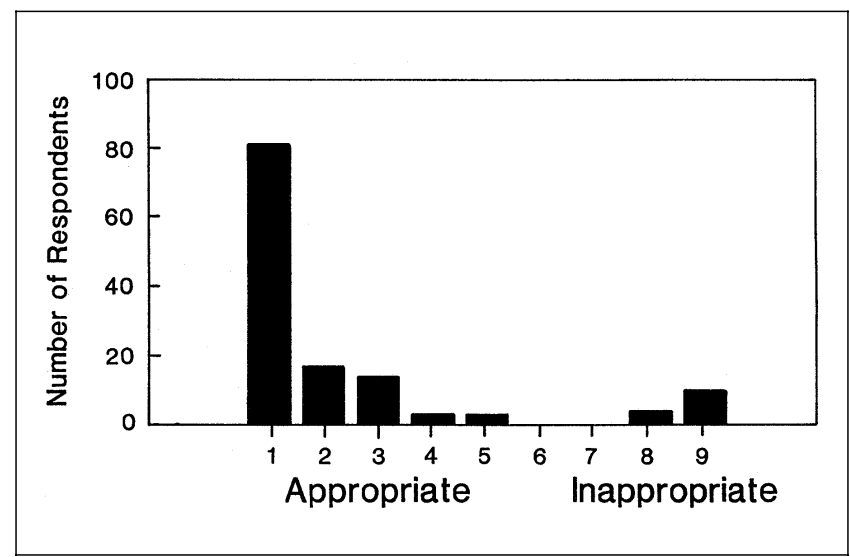

Figure 1) Distribution of appropriateness ratings by endoscopists for scenario 45 (follow-up of an asymptomatic patient with a not classically appearing ulcer). A total of 114 respondents considered this to be an appropriate indication for endoscopy

with more than 800 beds. More than half the physicians (52\%) performed at least 400 endoscopies per year but 25\% performed fewer than 200 per year.

Rating of RAND scenarios: The Appendix lists the 53 most frequently occurring appropriate, equivocal and inappropriate indications in the RAND study. It also shows the median rating by the study sample. Table 1 records the extent of agreement between the present study sample and the RAND study.

Five experienced endoscopists from the four major Alberta hospitals were asked to review the discrepancies and to identify possible reasons for any discrepancies. These endoscopists were not aware of the published comments $(7-10)$ regarding the RAND study. However, their comments concurred with published comments. A major reason for discrepancies was that medical treatment is more effective now than in the early 1980s and that failure to respond to therapy is more likely to indicate possible malignancy. There appears to be general consensus regarding the appropriateness of endoscopy in scenarios where there is a possibility of missing a malignancy. This concern is seen in the distribution of ratings for scenario 45, considered inappropriate by RAND (Figure 1). Endoscopists consider a repeat endoscopy appropriate when there is any concern about a gastric malignancy. 


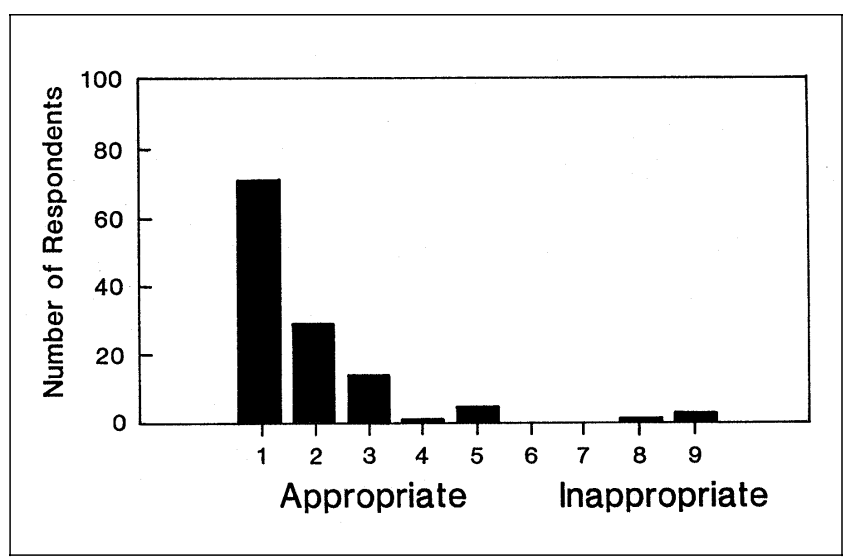

Figure 2) Distribution of appropriateness ratings by endoscopists for scenario 23 (evaluation of occult blood in stool, anemia and upper gastrointestinal symptoms). A total of 112 respondents considered this to be an appropriate indication for endoscopy

\section{TABLE 2}

Median RAND Corporation ratings compared with those from general internists who do not perform endoscopy

\begin{tabular}{lr}
\hline Considered appropriate by RAND & 18 \\
Considered appropriate by internists & 16 \\
Considered equivocal by internists & 2 \\
Considered equivocal by RAND & 16 \\
Considered appropriate by internists & 10 \\
Considered equivocal by internists & 4 \\
Considered inappropriate by internists & 2 \\
Considered inappropriate by RAND & 19 \\
Considered appropriate by internists & 2 \\
Considered equivocal by internists & 11 \\
Considered inappropriate by internists & 6 \\
\hline
\end{tabular}

\section{TABLE 3}

\section{Comparison of ratings by endoscopists and general} internists

\begin{tabular}{lrrcc}
\hline & & \multicolumn{3}{c}{ Endoscopists' ratings } \\
& & Appropriate & Equivocal & Inappropriate \\
\cline { 3 - 5 } & 25 & 2 & 1 \\
Internists' & Appropriate & 25 & 9 & 1 \\
ratings & Equivocal & 7 & 1 & 6 \\
\hline
\end{tabular}

Another reason for the discrepancies was the belief that too much emphasis was placed on a requirement for barium studies before performing endoscopy. This is demonstrated in scenario 28, considered equivocal by RAND, which outlines a patient with anemia and upper gastrointestinal symptoms (Figure 2). A clear majority of endoscopists considered this an appropriate use of endoscopy and would not require a barium series before performing the endoscopy.

Factors related to indication ratings: Median ratings for appropriateness were not related to time spent in clinical care, age or hospital size. Although a few statistically significant associations occurred (four for time spent in clinical care, two for age and four for hospital size), they are not reported because multiple tests were done. In that regard, one of every 20 tests will produce $\mathrm{P}<0.05$ merely by chance (11); for 53 items, three significant results can be expected due to chance alone. No association was significant at $\mathrm{P}<0.001$.

Seven significant relationships were found regarding attendance at an educational event. Physicians who attended educational events rated five items $(7,22,32,37$ and 42 in the Appendix) as significantly more appropriate versus physicians who had not attended such events. Interestingly, all these items included scenarios that referred to the results of barium studies or upper gastrointestinal series, or to the fact that these were not done. For two other items (numbers 52 and 53), those who attended educational events related the scenarios as less appropriate than those who did not attend.

Nine scenarios $(7,10,13,17,22,25,32,37$ and 42) were rated as significantly less appropriate by physicians who did fewer than 400 endoscopies per year compared with those who performed more. Five of these scenarios also showed differences with respect to attending educational events, and again all scenarios were related to barium studies or upper gastrointestinal series. In scenario 53 a reverse relationship was found.

Gastroenterologists rated 11 scenarios $(2,7,10,13,14,17$, $22,28,32,37$ and 45$)$ as more appropriate compared with physicians with other specialties. Most of these scenarios were also found to differ with respect to time spent in clinical care or attendance at an educational event. Eight scenarios $(5,29,38,39,49,50$ and 53$)$ were rated as less appropriate by gastroenterologists compared with physicians with other specialty areas. The majority of these scenarios dealt with follow-up of previous upper gastrointestinal series or endoscopy.

Comparison of ratings from endoscopists and general internists: Of the 39 eligible internists, 25 completed and returned the questionnaire (64\%). The extent of agreement between the internists and the RAND study is shown in Table 2. The appropriateness rankings using the nine-point scale were also analyzed in detail. In general, internists rated the indications as less appropriate versus ratings from endoscopists. Compared with ratings from endoscopists, internists rated 22 items as less appropriate, nine as more appropriate and 22 as equivocal. Of the 18 indications rated as appropriate by RAND, internists rated 10 indications as somewhat less appropriate than did endoscopists. Of the equivocal indications, eight were rated as less appropriate by internists than by endoscopists and two were rated as somewhat more appropriate. This pattern was not the same for the inappropriate indications. Four indications were rated as less appropriate by internists compared with ratings from endoscopists, but seven were rated as more appropriate $(38,39,46,50,51,52$ and 53). Not surprisingly, five of these related to the differences in ratings between gastroenterologists and other physicians performing endoscopy.

Differences between rankings from endoscopists and internists are summarized in Table 3 . The overall difference is significant; however, the small number of general internists 
may have prevented the detection of subtle differences. In 40 of 53 scenarios $(75 \%)$, endoscopists and general internists agreed on the appropriateness of the scenarios. In 12 scenarios, significant differences were present in ratings (on a scale from 1 to 9) from internists versus endoscopists. In 10 scenarios, the internists considered the indication as being somewhat less appropriate than did the endoscopists. Without exception these scenarios referred to situations in which the results of barium studies were normal, known or not done.

\section{DISCUSSION}

This is the first broadly based survey of the RAND indications in North America. In $60 \%$ of the scenarios, the endoscopists in our sample agreed with the RAND classification, in 30\% there was minor to moderate disagreement (a difference between appropriate and equivocal, or between equivocal and inappropriate) and in 10\% there was major disagreement (a difference between appropriate and inappropriate). For general internists, there was agreement with RAND in $49 \%$, minor to moderate disagreement in $47 \%$ and major disagreement in $4 \%$ of the scenarios. Although both groups were more inclined than the RAND study to rate more scenarios as appropriate, endoscopists tended to do so more than internists (difference was not significant).

The response rate (over $60 \%$ ) by both endoscopists and general internists is considered to be adequate for mailed surveys of physicians. The survey method did not allow collection of demographic data related to the nonresponders, and a possible selection bias cannot be excluded. A British study that compared the RAND scenarios for endoscopy with the evaluation of a panel of 16 British gastroenterologists $(12,13)$ also concluded that the major areas of disagreement were the undue emphasis on the results of prior barium studies and the importance of insufficient treatment in resolution of symptoms.

Several factors contribute to an explanation of these results. Endoscopy, a safe, sensitive and specific procedure (15) readily available and accessible to patients, is often performed on an out-patient basis. Therefore, it is not surprising that endoscopists are comfortable with the procedure and offer it readily. The finding that endoscopists who perform more procedures per year tend to regard more scenarios as appropriate than those who perform fewer procedures appears to confirm this.

Endoscopists' opinions and actions suggest that they put little reliance on barium studies and are not likely to demand them before endoscopy. This may be based on a perception of a lower sensitivity and specificity of barium studies, but may also reflect the ability of endoscopy to perform diagnostic or therapeutic manoeuvres. In this scenario avoidance of barium studies may save costs. Lastly, with the increased availability of additional gastroenterologists, family physicians may find it easier to refer to a gastroenterologist rather than obtaining a barium study.

As has been pointed out, concern related to the possibility of missing a malignancy appears to explain many discrep- ancies; early detection facilitates a better chance for a cure. Moreover, endoscopists may worry about professional embarrassment or chagrin about missing a malignant lesion in a patient especially referred to them for an endoscopic evaluation.

Despite these possible explanations for an increase in appropriate scenarios compared with results from the RAND study, endoscopists may be more aggressive because there is financial benefit attached to performing endoscopies. We evaluated this possibility by surveying a group of general internists who did not perform endoscopy. General internists, because they do not perform endoscopy, are often asked to sit on endoscopy audit committees. Their opinions related to endoscopy are important.

In general, the internists' ratings were closer to those of the endoscopists than those reported by RAND. This might suggest that financial motives are not an issue. However, because most training programs in internal medicine include rotations in gastroenterology, it is possible that the internists are only reflecting the biases they learned during that rotation. There were, however, some differences. General internists have more faith in the accuracy of barium studies and appeared to put greater reliance on radiological findings versus endoscopists. This difference may relate to the anecdotal experience of most experienced endoscopists who have endoscoped patients with normal barium examinations and identified significant pathology, including neoplasms. General internists may not encounter this problem as frequently as endoscopists.

An important consideration is that the disagreement cannot be extrapolated to the number of endoscopies performed. The RAND study showed that only a relatively small proportion of endoscopies $(17 \%)$ is done for inappropriate indications. In addition, it may be that some of the disagreement relates to scenarios that rarely occur in clinical practice. Finally, this study only considered the 53 published scenarios rather than the full set of 1069 indications.

Another possible explanation for changes in endoscopy use is awareness of the importance of Helicobacter pylori and gastrointestinal disease. Endoscopists may have altered their threshold for endoscopy in order to obtain evidence of whether a patient has biopsy or other evidence of an $\mathrm{H}$ pylori infection. The format of this study did not allow this possibility to be explored.

\section{CONCLUSIONS}

The results of this study demonstrate that equivocal and inappropriate ratings as developed by the RAND Corporation are not uniformly accepted by the endoscopy community in 1995. As the profession moves towards evidencebased medicine and clinical practice guidelines, a new approach - not based on consensus but rather on clinical evidence - will be required. Careful studies of patient outcome following endoscopy for specific indications adjusting for age and the presence of constitutional symptoms may be necessary. The development of such evidence-based guidelines for endoscopy should be a priority for the profession. 


\section{APPENDIX \\ Median ratings by physicians in study sample compared with RAND Corporation study ratings}

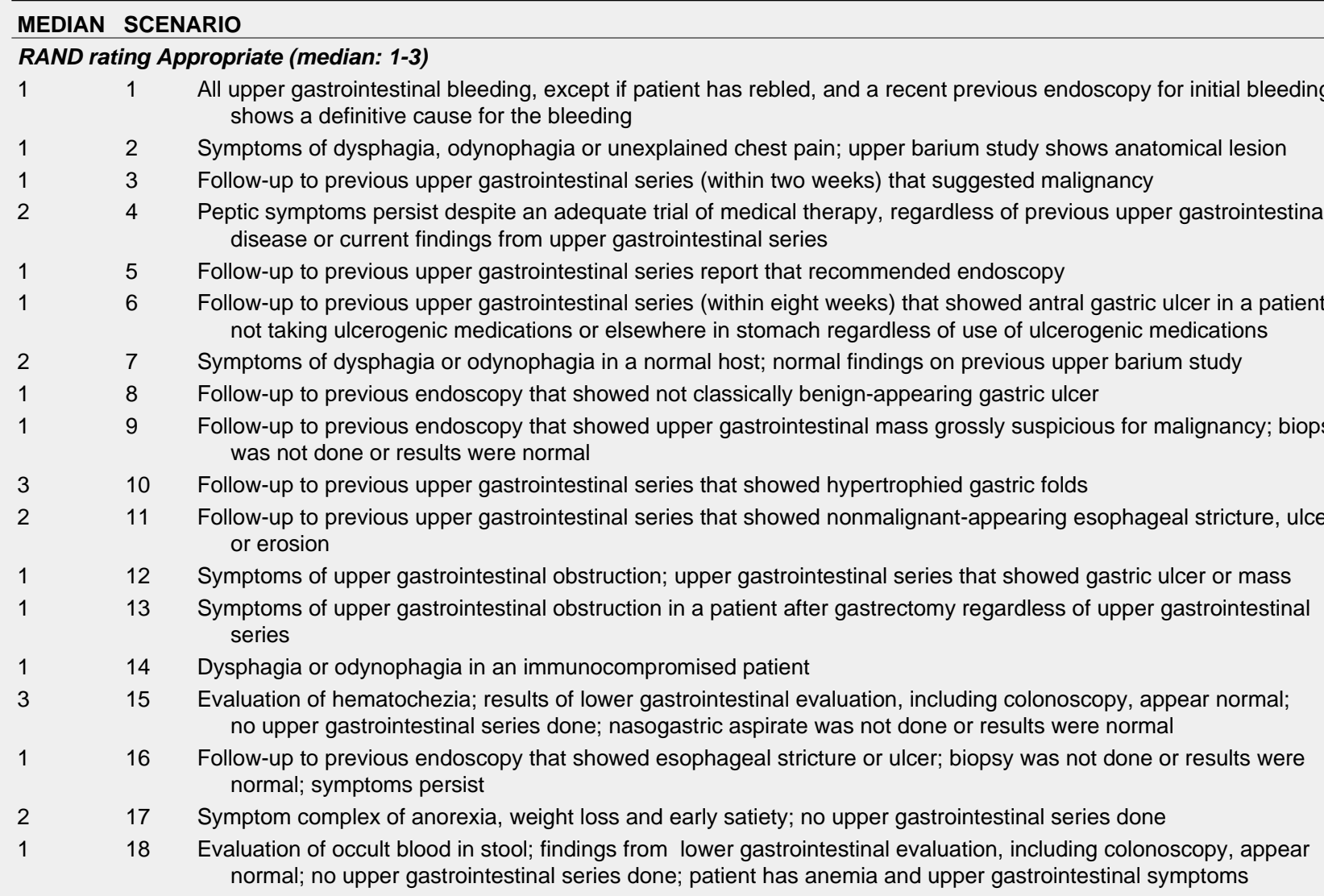

RAND rating Equivocal (median: 4-6)

519 Peptic symptoms persist after inadequate trial of medical therapy*; no history of peptic disease, and upper gastrointestinal series not done

Follow-up to previous upper gastrointestinal series that showed antral deformity that worsened in relation to a previous upper gastrointestinal series

Evaluation of occult blood in stool; lower gastrointestinal work-up without colonoscopy shows no bleeding source; patient has anemia and upper gastrointestinal symptoms

Symptoms of dysphagia or odynophagia in normal hosts; upper barium study shows motility disorder

Follow-up to a previous endoscopic finding of gastric ulcer not classically benign on previous endoscopy; patient has no symptoms

Evaluation of occult blood in stool; lower gastrointestinal work-up, including colonoscopy, shows no potential bleeding source; patient has anemia but no upper gastrointestinal symptoms

Peptic symptoms persist after inadequate trial of medical therapy*; patient had gastrectomy; upper gastrointestinal series not done

Follow-up to previous endoscopic finding of esophageal ulcer or stricture with normal biopsy findings and no symptoms

Follow-up to previous upper gastrointestinal series that showed benign-appearing antral gastric ulcer in a patient taking ulcerogenic medication

Evaluation of occult blood in stool; lower gastrointestinal work-up, including colonoscopy, shows no potential bleeding source; patient has anemia and upper gastrointestinal symptoms

Follow-up to previous upper gastrointestinal series that showed esophagitis

Evaluation of hematochezia; results of a lower gastrointestinal work-up without colonoscopy appear normal; no upper gastrointestinal series done; nasogastric aspirate not done or results were normal

Symptoms of upper gastrointestinal obstruction; upper gastrointestinal series not done

Symptoms of upper gastrointestinal obstruction; upper gastrointestinal series shows no anatomical lesion; patient has no diabetes, no use of motility-impairing drugs and no history of duodenal ulcer or previous gastrectomy

Symptom complex of anorexia, early satiety and weight loss persisting six months or more; upper gastrointestinal series shows normal findings

34 Evaluation of occult blood in stool; results of a lower gastrointestinal work-up, including colonoscopy, show no potential bleeding source; patient has no anemia and no upper gastrointestinal symptoms; upper gastrointestinal series not done or shows nonmalignant pathological findings 


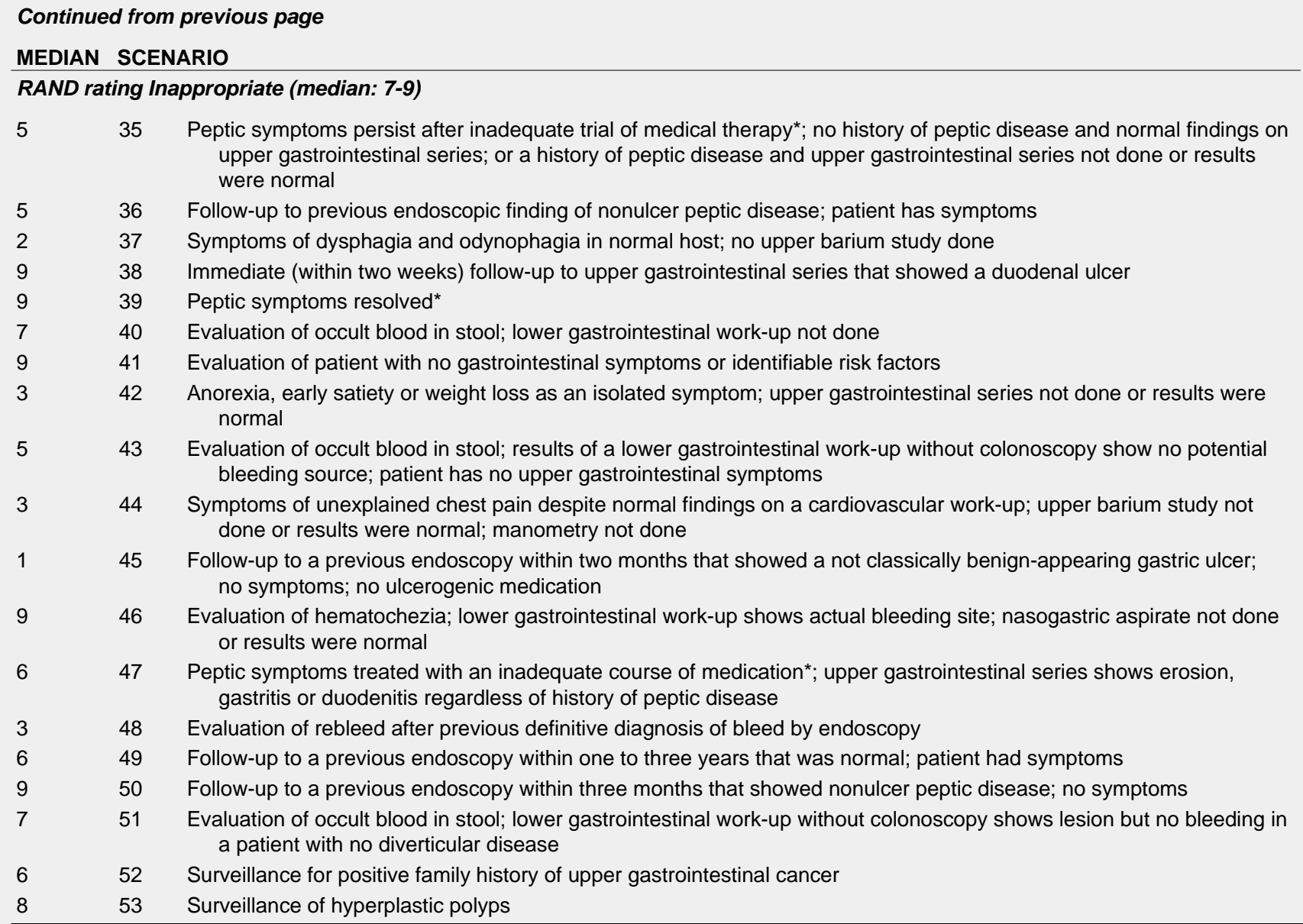

*All patients with any evidence of bleeding, obstruction, significant weight loss, early satiety or anorexia were considered to have had adequate therapy for these symptoms before an endoscopy was done

ACKNOWLEDGEMENTS: This study was funded by the Alberta Health Research and Innovation Fund.

Participating physicians in the Alberta Endoscopy Project - Foothills Hospital (Calgary): Drs Don Buie, Noel Hershfield, Sam Lee, Keith MacCannell, Gary May, Jon Meddings, Lorne Price, Eldon Shaffer, Lloyd Sutherland and Mark Swain; Calgary General Hospital (Calgary): Drs Sid Bass, Phil Blustein, Ron Bridges, John Heine, Tom Lay and Guido Van Rosendaal; Royal Alexandra Hospital (Edmonton): Drs Robert Bailey, Duncan Campbell, James Ferguson, Dennis Jirsch, Vernon Kumpula, William Orrom, Clive Robertson, Ken Schmidt, Joe Siegenberg, Dennis Todoruk, Deiworth Tusz and Ernest Wiens; University of Alberta Hospital (Edmonton): Drs Richard Fedorak, Eoin Lalor, Dan Sadowski, Eric Semlacher, Alan Thomson and Bruce Yacyshyn.

\section{REFERENCES}

1. Scott B. Endoscopic demands in the 90's. Gut 1990;31:125-6.

2. Sapienza PE, Levine GM, Pemerantz S, Davidson JH, Weinryb J, Glassman J. Impact of a quality assurance program on gastrointestinal endoscopy. Gastroenterology 1992;102:387-93.

3. Mann J, Holdstock G, Harman M, Machin D, Loehry CA. Scoring system to improve cost-effectiveness of open access endoscopy. BM] 1983;287:937-40.

4. Holdstock G, Bruce S. Endoscopy and gastric cancer. Gut $1981 ; 22: 673-6$
5. Holdstock G, Colley S. Failure of increased use of endoscopy to influence complication rate in peptic ulcer disease. BMJ 1983;287:393-4.

6. Kahn KL, Kosecoff J, Chassin MR, Solomon DH, Brook RH. The use and misuse of upper gastrointestinal endoscopy. Ann Intern Med 1988;109:664-70.

7. Feldman RE. Upper gastrointestinal endoscopy. Ann Intern Med 1989;110:244. (Lett)

8. Spiro HM. Upper gastrointestinal endoscopy. Ann Intern Med 1989;110:246. (Lett)

9. Kandel G. Upper gastrointestinal endoscopy. Ann Intern Med 1989;110:244-5. (Lett)

10. Morrissey JF. The problem of the inappropriate endoscopy. Ann Intern Med 1988;109:605-6. (Edit)

11. Ware JH, Mostellar F, Ingelfinger JA. P Values. In: Bailar JC, Mosteller F, eds. Medical Uses of Statistics. Waltham: NEJM Books, 1986:149-69.

12. Murray FE, Kenny C, Hawkey CJ, Logan RFA, Nottingham Gut Group. A prospective audit of the appropriateness of upper gastrointestinal endoscopy using the RAND criteria. Gut 1992;33:514. (Abst)

13. Murray FE, Kenny C, Hawkey CJ, Logan RFA, Nottingham Gut Group. A prospective blinded evaluation of the RAND system to determine appropriateness of upper gastrointestinal endoscopy. Gut 1992:33:515. (Abst)

14. Tytgat GNJ. Upper gastrointestinal endoscopy. In: Yamada T, Alpers DH, Owyang C, Powell DW, Silverstein FE, eds. Textbook of Gastroenterology. Philadelphia: Lippincott, 1991:2245. 


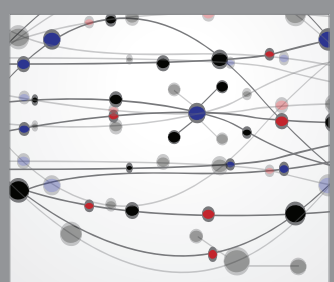

The Scientific World Journal
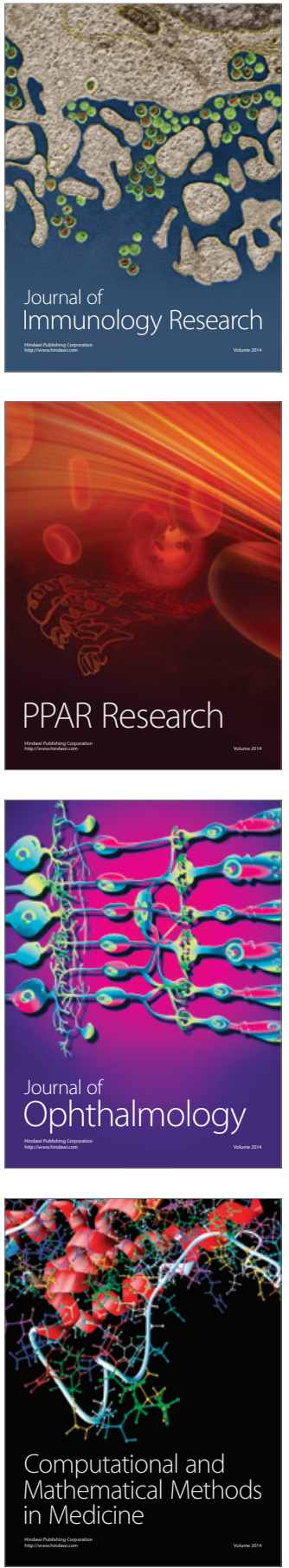

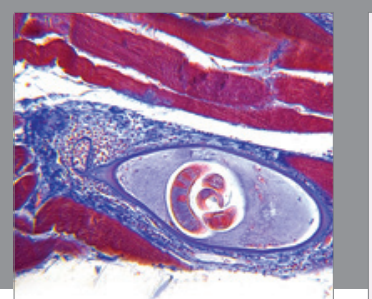

Gastroenterology Research and Practice

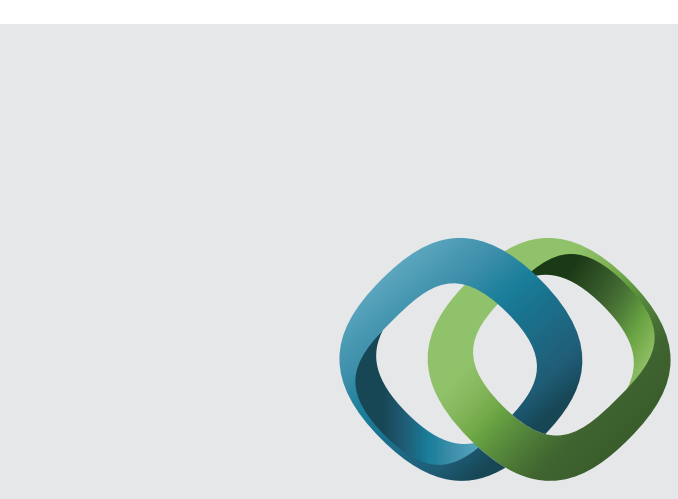

\section{Hindawi}

Submit your manuscripts at

http://www.hindawi.com
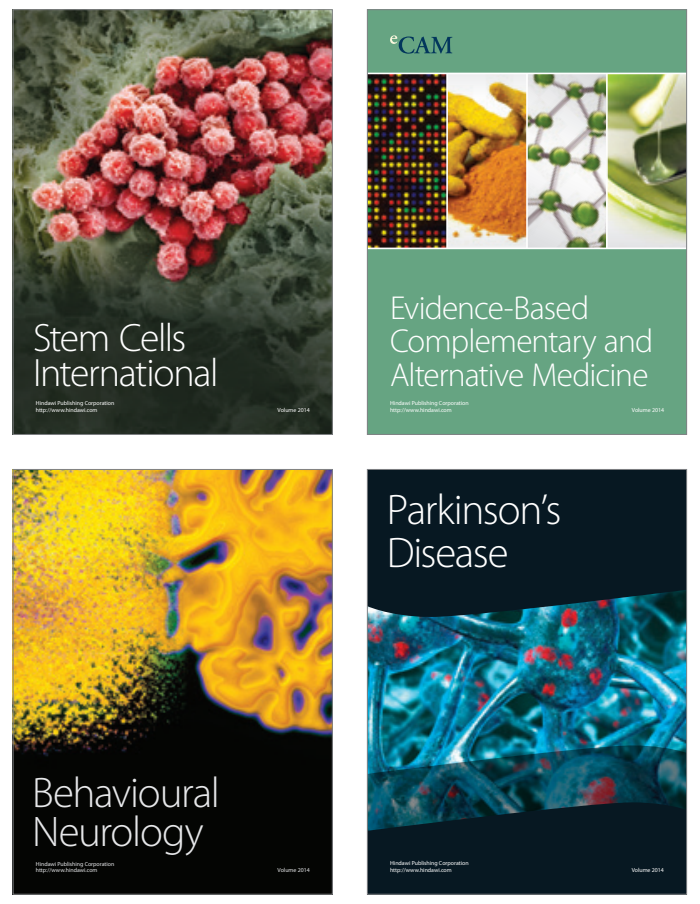
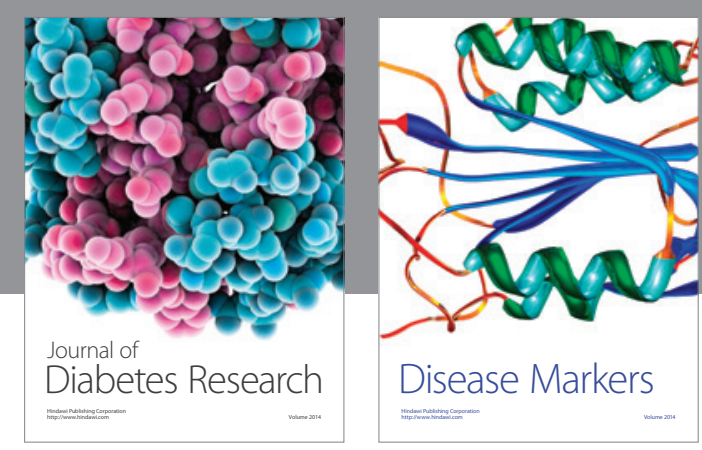

Disease Markers
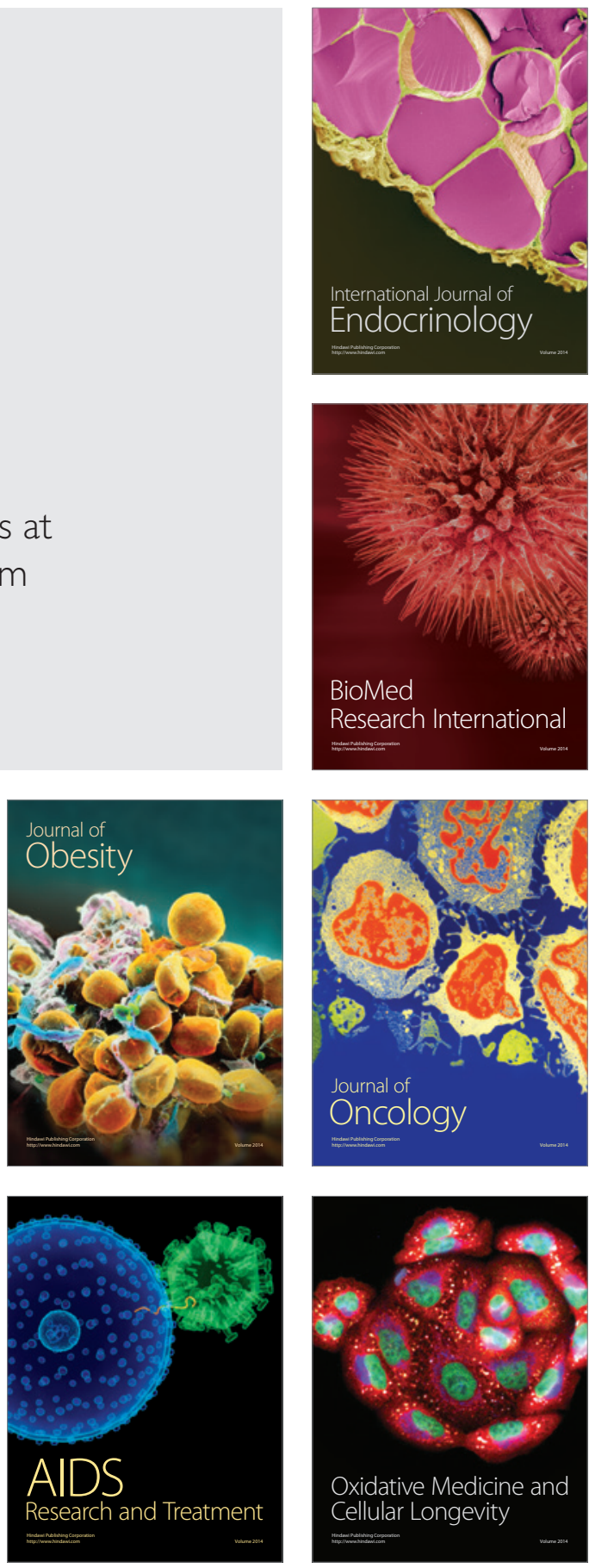